\title{
The Relationship between Hope and Successful Aging of Elders: A Moderation Model of Appearance Management Behavior
}

\author{
노인의 희망과 성공적 노화의 관계에서 \\ 외모관리행동의 조절효과 \\ Yeoun Kyoung Hwang ${ }^{1}$, Chang Seek Lee ${ }^{2}$ \\ 황연경 1 , 이창식 2 \\ ${ }^{1}$ Professor for Academic Research, Multicultural Education and Welfare Institute, Hanseo University, \\ Korea,01020707980@ hanmail.net \\ ${ }^{2}$ Professor, Dept. of Health, Counseling and Welfare, Hanseo University, Korea, \\ lee1246@hanmail.net \\ Corresponding author: Chang Seek Lee
}

\begin{abstract}
The purpose of this study was to verify the moderating effect of appearance management behavior on the link between hope and successful aging of the elderly. The research questions to achieve these objectives are as follows. First, what is the correlation between hope, appearance management behavior, and successful aging? Second, what is the moderating effect of appearance management behavior on the relationship between hope and successful aging? For the analysis, SPSS window version 25.0 and PROCESS macro version 3.5.3 were used, and frequency analysis, reliability analysis, correlation analysis, moderation effect analysis and bootstrap method were performed. As a result of the study, first, there were positive correlations between hope, appearance management behavior, and successful aging. Second, the interaction term between hope and appearance management behavior had a positive effect on successful aging, and thus the moderating effect of appearance management behavior on the relationship between hope and successful aging was verified. The conditional effects of hope according to the moderating variable value were significant when the appearance management behavior was low (M-1SD), average (M), and high (M+1SD). The results indicate that the higher the appearance management behavior, the higher the conditional effect of hope. This result is intended to be used as a model for successful aging improvement using the appearance management behavior of the elderly.
\end{abstract}

Keywords: Hope, Successful Aging, Appearance Management Behavior, PROCESS Macro, Moderation Effect, Conditional Effect, Elderly

요약: 이 연구는 노인의 희망과 성공적 노화의 관계에서 외모관리행동의 조절효과를 검증하는데 목적이 있다. 이러한 연구 목적 달성을 위한 연구 문제는 다음과 같다. 첫째, 희망, 외모관리행동 및 성공적 노화 간의 상관관계는 어떠한가? 둘째, 희망과 성공적 노화의 관계에서 외모관리행동의 조절효과는 어떠한가? 분석을 위해 SPSS window version 25.0과 PROCESS macro version 3.5.3을 활용하였고, 자료분석을 위하여 빈도분석, 신뢰도분석, 상관분석,

Received: March 27, 2021; 1st Review Result: May 10, 2021; 2nd Review Result: June 23, 2021 Accepted: July 31, 2021 
조절효과 분석, 부트스트랩이 사용되었다. 연구 결과, 첫째, 희망, 외모관리행동 및 성공적 노화 간에 모두 정적으로 유의미한 상관관계가 있었다. 둘째, 희망과 외모관리행동의 상호작용항은 성공적 노화에 정적 영향을 미쳐, 희망과 성공적 노화의 관계에서 외모관리행동의 조절효과가 검증되었다. 조절변수 값에 따른 희망의 조건부 효과는 외모관리행동이 낮을 때(M-1SD), 평균일 때(M)와 높을 때(M+1SD) 모두 유의미하였다. 이는 외모관리행동 높아질수록 희망의 조건부 효과는 증가함을 의미한다. 본 논문의 결과는 노인들의 외모관리행동을 활용한 성공적 노화 증진을 위한 모델로 활용될 것이다.

핵심어: 희망, 성공적 노화, 외모관리행동, 프로세스 매크로, 조절효과, 조건부 효과, 노인

\section{1. 서론}

노화는 누구도 피할 수 없는 자연스러운 현상이다. 노년기는 삶에서 가장 오랜 기간을 차지하고, 노화는 멈추지 않는다. 그래서 인간은 잘사는 것만큼이나 잘 늙어가는 것이 매우 중요하다. 성공적 노화는 잘 늙어가는 것을 의미한다. 노화가 성공적으로 진행될 수 있다면, 노화는 더이상 슬프고 서글픈 개념이 아닐 것이다. 학계에서도 노화를 상실이나 손실이 아닌 성공이나 성장으로 바라보려는 시도가 있었는데, 이는 성공적 노화에 관한 연구로 이어졌다. 성공적 노화는 건강한 노화나 긍정적인 노화 및 효과적 노화로 사용되기도 한다[1]. 이러한 성공적 노화는 사회·심리적 변인들과 높은 연관성이 있는 것으로 밝혀졌다[2].

2차 세계대전 이후 인간이 지닌 긍정적인 측면, 즉 강점과 자원에 초점을 두어야 한다는 심리학적 반성에서 긍정심리학이 창시되었다. 희망은 긍정심리학에서 매우 중요하게 다루어지는 변인으로 꼽히며, 다양한 분야에서 연구가 이루어지고 있다. 희망은 목표를 설정하는 주도사고(agency thinking)와 설정한 목표를 달성하기 위해 계획하는 경로 사고(pathways thinking)로 구성되며, 긍정적으로 동기가 유발된 상태를 의미한다[3]. 희망을 포함한 긍정심리자본이 성공적 노화에 직간접적으로 영향을 주는 것으로 보고된 바 있다[4]. 그러나 노인의 희망과 성공적 노화의 관계를 직접적으로 다룬 연구는 거의 찾아보기 어렵다. 이에 본 연구에서는 희망이 성공적 노화를 설명해주는 원인이 될 것으로 예측하여, 희망을 독립변인으로 성공적 노화를 종속 변인으로 설정하였다.

한편 외모는 선천적으로 타고나지만 어떻게 관리하느냐에 따라 변화될 수 있는데, 자신의 외모를 긍정적으로 만들고자 노력하는 일련의 과정들을 외모관리행동이라 한다. 외모관리행동과 심리 변인 간에는 밀접한 관련이 있는데, 인간은 외모관리행동을 통해 스트레스 감소, 외모만족도 증진 및 행복감을 증가시키며, 이렇게 얻게 되는 심리적 효용 때문에 외모관리행동을 하게 된다[5].

본 연구의 핵심은 ‘무엇이 성공적 노화를 가능하게 할 것인가?’에 대한 대안을 검증하고 제시하는 것이다. 노인의 희망과 성공적 노화 간에 정적 인과관계가 검증된다면, 희망 수준이 낮은 경우 성공적 노화를 높일 수 있는 대안이 필요하며, 그 역할을 외모관리행동이 할 것으로 예측하였다.

따라서 노인의 희망이 성공적 노화에 미치는 영향에서 외모관리행동의 조절효과를 검증하여, 외모관리행동을 활용한 성공적 노화 증진 모델을 제공하는 데 이 연구의 목적이 있다. 
연구 목적 달성을 위한 연구 문제는 다음과 같다.

첫째, 희망, 외모관리행동 및 성공적 노화 간의 상관관계는 어떠한가?

둘째, 희망과 성공적 노화의 관계에서 외모관리행동의 조절효과는 어떠한가?

\section{2. 이론적 배경}

\section{1 희망과 성공적 노화의 관계}

인간은 목표 지향적인 존재인데 희망은 목표 획득에 대한 동기와 목표 성취에 대한 방법을 모두 포함한다. 이 둘은 will과 way로 상호작용을 하고, 이 둘 중 요인 한 가지가 없으면 성공적인 목표 달성은 어렵다[3]. 즉, 희망은 원하는 목표를 설정하고, 이를 달성하기 위하여 노력하는 마음 및 정신적 에너지이다[6]. 희망 수준이 높은 사람은 그렇지 않은 사람에 비해서 높은 삶의 만족감과 긍정적인 심리 상태를 갖게 된다[7]. 이러한 맥락에서 희망이 노인의 부정적인 정서를 감소시킨다[8].

노인들의 희망이 중요한 이유는 성공적 노화로 이어지기 때문이다. 노화를 경험하는 동일한 상황에서도 누군가는 노화를 성공과 성장이라는 긍정적인 측면에 초점을 둘 것이고, 또 다른 누군가는 퇴화와 상실 등 부정적인 측면에 초점을 둘 것이다. 결국 이러한 마이드셋에 따라 성공적 노화 정도가 달라질 것이다.

성공적 노화는 노년학의 주요 관심 주제로 다루어지고 있다. Rowe와 Kahn[9]에 따르면 노화는 성공적 노화와 보통의 노화로 대별되는데, 질병과 장애로 어려움을 격고, 신체적 기능과 인지적 기능 감소로 사회 활동이 부족한 것은 보통의 노화인 반면 이에 안주하지 않고 극복하거나 극복하려고 노력하는 것은 성공적 노화라고 하였다.

관련 연구를 살펴보면, 신체상은 희망을 경유하여 성공적 노화에 간접적으로 영향을 미쳤고[10][11], 고령 학습자의 긍정심리자본은 성공적 노화에 직, 간접적으로 영향을 미쳤다[4].

본 연구에서도 희망과 성공적 노화의 인과관계를 파악하고자 하였다.

\section{2 외모관리행동의 조절효과}

외모는 한 개인의 심리 정서 상태를 표출하는 창구이다. 인간은 무의식적으로 자신이 다른 사람에게 어떻게 보이는가에 대한 질문을 하면서, 자기가 원하는 이상적인 외모를 연출하고자 노력한다. 외모를 관리하는 것은 한 개인이 타인과의 관계에서 자기만의 개성을 표현해 나가는 과정이고, 사회생활에서 자신을 알리고 표현하는 방법 중 하나이다[12]. 외모관리행동은 다른 사람에게 자신의 외모를 원하는 대로 비치기 위하여 의복이나 화장품, 액세서리 등을 사용하는 것으로[13], 특히 노인들은 노화로 인해 신체적 변화를 많이 느끼기 때문에 젊고 아름다운 외모를 지향하며 나이보다 젊게 보이고 싶어 하는 욕구가 있다[14].

반면, 외모관리행동의 조절효과를 다룬 연구는 거의 없다. 동안 메이크업 인식과 주관적 행복감의 관계에서 외모관리행동의 조절효과가 있었고[15], 노인의 신체이미지와 성공적인 노화의 관계에서 외모관리행동이 조절 매개하였다는 연구[11]가 있다. 이에 희망이 성공적 노화를 증진하는 원리는 적극적인 외모관리 행위에 따라 얼마든지 달라질 수 있으리라 예측된다. 따라서 본 연구에서는 외모관리행동이 희망과 성공적 노화의 
인과관계에서 조절 역할을 하는지를 파악하고, 긍정적인 인과관계를 강화할 대안적 요인인가를 검증하고자 한다.

\section{3. 연구 방법}

\section{1 연구 모형}

이 연구의 모형은 PROCESS macro ver.3.5.3의 model 1번인 조절효과 분석 절차에 따라 [그림 1]과 같이 설정하였다.

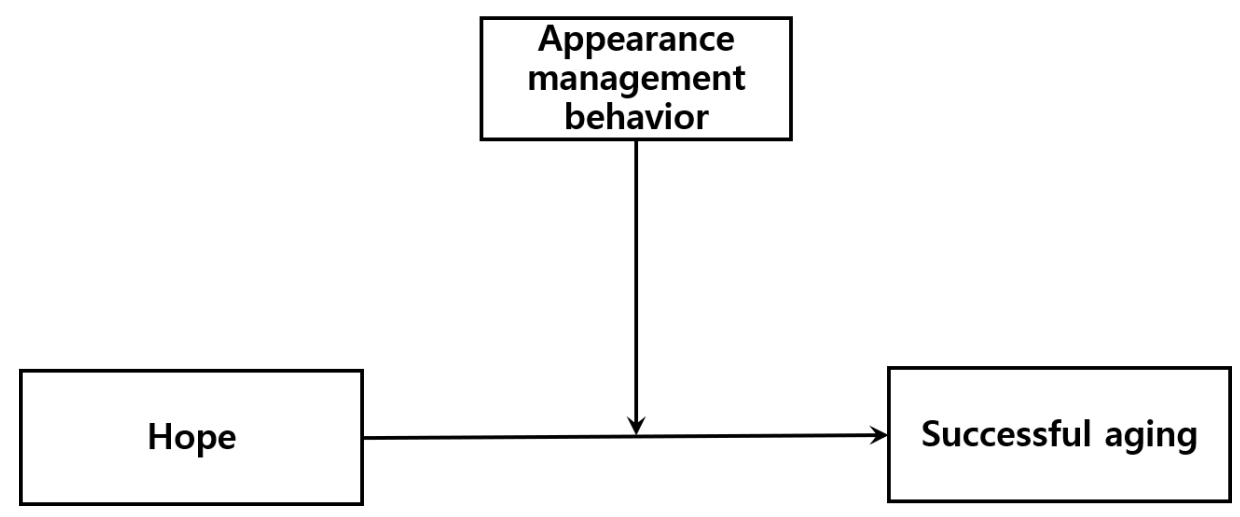

[그림 1] 연구 모형

[Fig. 1] Research Model

\section{2 조사 대상 및 데이터 수집 방법}

조사대상은 충남의 $\mathrm{D}$ 시에 거주하는 노인을 유의표집하였다. $\mathrm{G}^{*}$ Power program을 이용한 적절한 표본 수는 최소 202 명이 산출되었다. 그러나 변인 간의 관계 및 역할을 파악하는 연구이므로 충분한 표본을 확보하기 위하여 500 명을 목표로 하였다.

이 연구는 IRB 심의 대상으로 보건복지부 지정 공용기관생명윤리위원회의 승인(P01202005-22-002)을 받았다. 자료는 연구자가 직접 설문지를 배포하고 수거하였고, 조사 기간은 2020년 5월부터 약 6개월간 진행하였으며, 불성실한 설문지들을 제외하고, 422 부를 최종 분석에 활용하였다.

조사대상자는 여자 노인이 $61.2 \%$, 남자 노인 $38.8 \%$ 이었고, 연령은 70 세 74 세가 $47.0 \%$ 로 가장 비중이 높았고, 75 세 이상이 $45.6 \%$ 로 두 번째로 많았다. 또한 가족 형태는 현재 배우자와 함께 거주한다는 응답자가 $62.1 \%$ 로 가장 많은 비중을 차지했다.

\section{3 조사 도구}

본 연구에 사용한 조사 도구는 희망, 외모관리행동, 성공적 노화 및 인구학적 특성들이다. 인구학적 특성들은 성별, 연령, 가족 형태 등으로 구성하였다.

\subsection{1 희망}

희망을 측정하기 위해 Snyder와 동료들이[3] 개발한 희망척도를 최유희 등[16]이 번안한 
한국형 희망 척도(K-DHS) 8 문항을 사용하였다. 각 문항은 5점 리커트 척도이고, '전혀 그렇지 않다 $=1$ 점'부터 '매우 그렇다 $=5$ 점'까지이며, 점수가 높을수록 희망의 수준이 높음을 의미한다. 이 연구에서 희망의 신뢰도 Cronbach's $\alpha$ 는 .892이었다.

\subsection{2 외모관리행동}

외모관리행동은 선행연구를 토대로 Hwang과 Lee[15]가 사용한 척도로 측정하였다. 이 척도는 외모 평가와 외모 지향성으로 구성되어 있다. 각 문항은 5점 리커트 척도이고, '전혀 그렇지 않다 $=1$ 점'부터 '매우 그렇다 $=5$ 점'까지이며, 점수가 높을수록 외모관리행동의 수준이 높음을 의미한다. 이 연구에서 외모관리행동의 신뢰도 Cronbach's $\alpha$ 는 .912이었다.

\subsection{3 성공적 노화}

성공적 노화는 이창식[17]이 사용한 17 문항을 대상에 맞게 수정 및 보완하여 측정하였다. 이 척도는 '건강하고 원만한 가족관계'와 '안정적인 주거와 잔존 능력', ‘목적이 있는 삶’인 3 개의 하위 영역으로 구성되어 있다. 각 문항은 5 점 리커트 척도이고, ‘전혀 그렇지 않다=1점’부터 ‘매우 그렇다 $=5$ 점'까지이며, 점수가 높을수록 성공적인 노화 수준이 높다는 것을 의미한다. 이 연구에서 성공적 노화의 신뢰도 Cronbach's $\alpha$ 는 .957 이었다.

\section{4 자료 분석}

본 연구는 SPSS Window. 25와 Hayes[18]의 PROCESS macro 3.5.3을 활용하여 신뢰도 분석, 빈도 분석 및 조절효과 분석을 하였다. 조절효과 검증은 부트스트랩 방법을 활용하였고, 신뢰구간은 $95 \%$, 샘플 수는 5,000 회로 지정하였으며, 분석 전 독립변인과 조절변인은 평균 중심화하였다.

\section{4. 연구 결과}

\section{1 상관관계 및 기술통계 분석}

희망, 외모관리행동 및 성공적 노화 간 상관관계를 파악하기 위해 Pearson 이변량 상관 분석을 하였고, 결과는 [표 1]과 같다. 희망, 외모관리행동 및 성공적 노화 간에는 모두 통계적으로 유의미한 정적 상관관계가 있었다. 특히 성공적 노화와 희망 간에는 가장 높 은 상관관계가 있었고 $(r=.424, p<.01)$, 그다음은 희망과 외모관리행동 $(r=.305, p<.01)$, 외모관 리행동과 성공적 노화 $(r=.187, p<.01)$ 순으로 높았다.

기술통계 결과 성공적 노화의 평균값이 4.204 로 가장 높았고, 그다음은 희망으로 3.423 였다.

[표 1] 상관관계 및 기술통계

[Table 1] Correlation and Descriptive Statistics

\begin{tabular}{c|c|c|c}
\hline & Hope & $\begin{array}{c}\text { Appearance Management } \\
\text { Behavior }\end{array}$ & Successful Aging \\
\hline Hope & 1 & & \\
\hline
\end{tabular}




\begin{tabular}{c|c|c|c}
\hline $\begin{array}{c}\text { Appearance Management } \\
\text { Behavior }\end{array}$ & $.305^{* *}$ & 1 & \\
\hline Successful Aging & $.424^{* *}$ & $.187^{* *}$ & 1 \\
\hline $\mathrm{M}$ & 3.423 & 3.017 & 4.204 \\
\hline $\mathrm{SD}$ & .5958 & .6794 & .6340 \\
\hline
\end{tabular}

${ }^{* *} p<.01$

\section{2 외모관리행동의 조절효과}

희망과 성공적 노화의 관계에서 외모관리행동의 조절효과를 파악하기 위해 Hayes[17]가 제안한 PROCESS macro for SPSS의 모델 1번의 절차에 따라 분석하였다. 검증 시 부트스트 랩을 활용하였고, 신뢰 구간은 $95 \%$, 그리고 샘플 수는 5,000 개로 지정하였으며, 성공적 노화를 제외한 변수는 평균 중심화하였다. 조절효과를 분석한 결과는 [표 1], [그림 2]에 제시하였다.

희망은 성공적 노화에 정적으로 유의미한 영향을 미쳤으나 $(.4684, p=.0000)$, 조절변인인 외모관리행동은 성공적 노화에 영향을 미치지 않았다(.0385, $p=.3820)$.

희망과 외모관리행동의 상호작용항은 성공적 노화에 유의미한 영향을 미쳤고(.1148, $p=.0255)$, 상호작용 항에 따른 $\mathrm{R}^{2}$ 의 증가량 $\left(\triangle \mathrm{R}^{2}=.0097, p=.0255\right)$ 도 유의미하였다. 즉, 외모 관리행동은 희망과 성공적 노화의 관계를 조절하였다.

[표 2] 조절효과 분석

[Table 2] Analysis of Moderating Effect

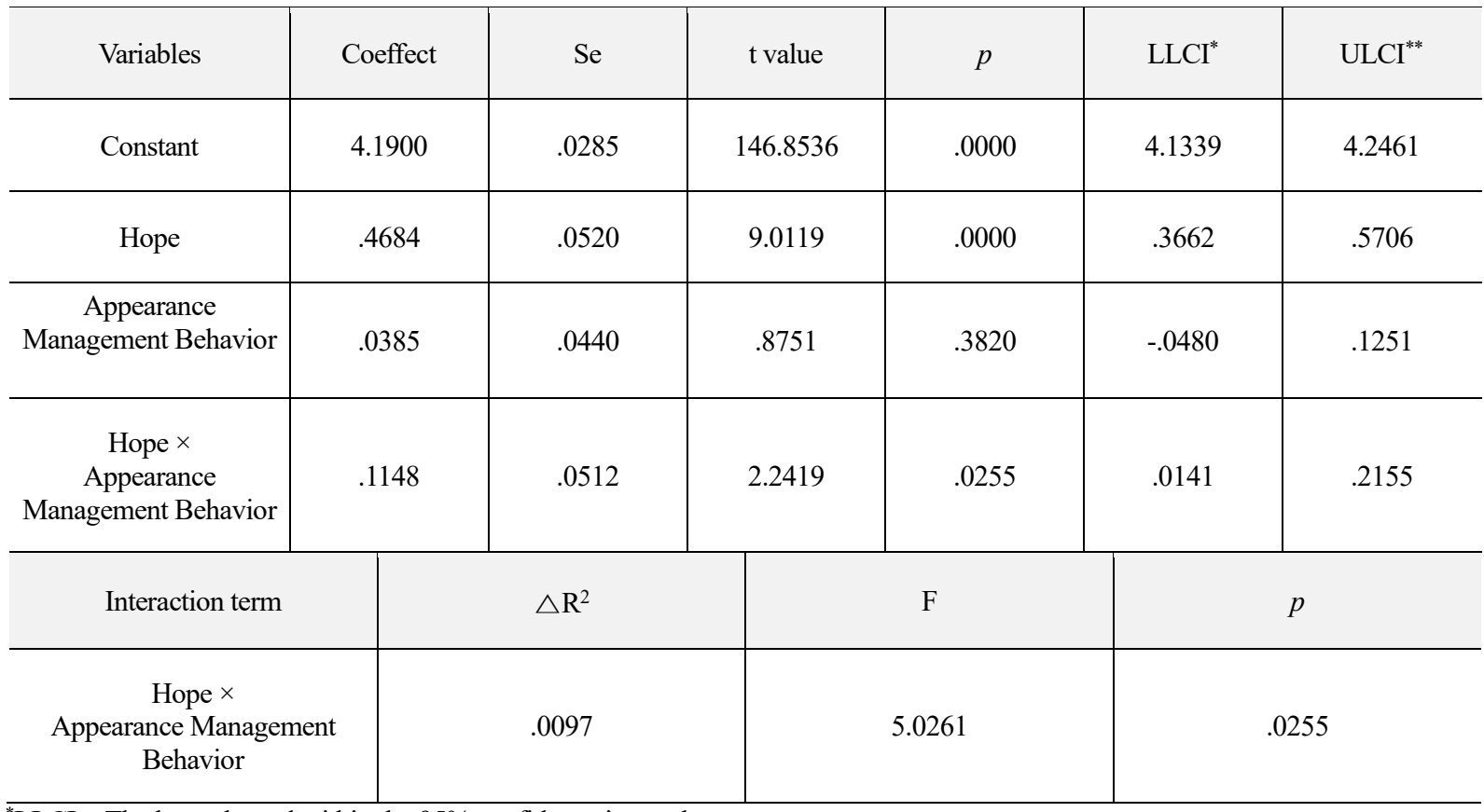

${ }^{*} \mathrm{LLCI}=$ The lower bound within the $95 \%$ confidence interval

${ }^{* *} \mathrm{ULCI}=$ The upper bound within the $95 \%$ confidence interval 


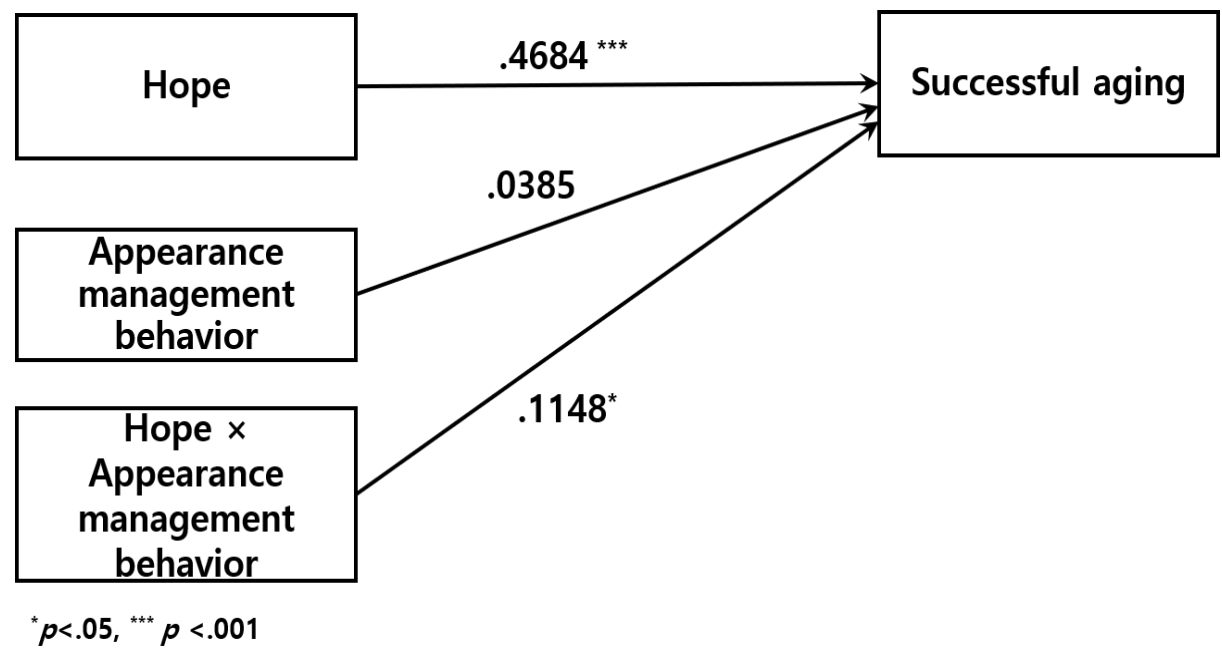

[그림 2] 조절효과 통계 모형

[Fig. 2] Moderating Effect Statistical Model

앞서 희망과 성공적 노화의 관계에서 외모관리행동의 조절효과가 확인되어 외모관리행 동의 조건부 효과를 분석하였고 결과는 [표 3]과 같다.

외모관리행동 값에 따라 3 개의 조건 $(\mathrm{M} \pm \mathrm{SD}, \mathrm{M})$ 을 주었고, 외모관리행동 값에 따른 희망 의 조건부 효과는 외모관리행동이 낮을 때(M-1SD), 평균일 때(M)와 높을 때(M+1SD) 모 두 유의미하였다 $(p=.0000)$. 외모관리행동 높아질수록 희망의 조건부 효과는 증가하였다.

조명등 분석법인 Johnson-Neyman 분석을 통해 희망의 조건부 효과의 유의성 영역을 파 악하였다. 외모관리행동 값 -2.0176 부터 1.9199 까지 전 영역에서 희망의 조건부 효과는 유의미하였고, 이 범위에서 통계적 유의성이 전환된 지점은 없었다. 즉, 전 영역에서 외 모관리행동 값이 증가할 때 희망의 조건부 효과가 증가하는 것으로 나타났다.

[표 3] 외모관리행동 값에 따른 희망의 조건부 효과

[Table 3] Conditional Effects of Hope at values of Appearance Management Behavior

\begin{tabular}{c|c|c|c|c|c|c}
\hline $\begin{array}{c}\text { Appearance } \\
\text { Management } \\
\text { Behavior }\end{array}$ & Effect & Se & t value & $p$ & LLCI $^{*}$ & ULCI $^{* *}$ \\
\hline. .6794 & .3904 & .0522 & 7.4794 & .0000 & .2878 & .4930 \\
\hline .0000 & .4684 & .0520 & 9.0119 & .0000 & .3662 & .5706 \\
\hline .6794 & .5464 & .0714 & 7.6512 & .0000 & .4060 & .6868 \\
\hline
\end{tabular}

Appearance Management Behavior defining Johnson-Neyman Significance Region(s)

\begin{tabular}{c|c|c|c|c|c|c}
\hline $\begin{array}{c}\text { Appearance } \\
\text { Management } \\
\text { Behavior }\end{array}$ & Effect & $\mathrm{F}$ & $\mathrm{t}$ value & $p$ & LLCI $^{*}$ & ULCI $^{* *}$ \\
\hline-2.0176 & .2367 & .0993 & 2.3852 & .0175 & .0416 & .4318 \\
\hline
\end{tabular}




\begin{tabular}{c|c|c|c|c|c|c}
\hline-1.8207 & .2593 & .0906 & 2.8616 & .0044 & .0812 & .4375 \\
\hline-1.6238 & .2820 & .0823 & 3.4245 & .0007 & .1201 & .4438 \\
\hline-1.4269 & .3046 & .0745 & 4.0890 & .0001 & .1582 & .4510 \\
\hline-1.2301 & .3272 & .0672 & 4.8664 & .0000 & .1950 & .4593 \\
\hline$:$ & $:$ & $:$ & $:$ & $:$ &. & .4221 \\
\hline 1.1324 & .5984 & .0897 & 6.6717 & .0000 & .4278 & .8142 \\
\hline 1.5262 & .6210 & .0983 & 6.3184 & .0000 & .4747 \\
\hline 1.7231 & .6663 & .1162 & 5.7337 & .0000 & .4378 & .8543 \\
\hline
\end{tabular}

${ }^{*} \mathrm{LLCI}=$ The lower bound within the $95 \%$ confidence interval

${ }^{* *} \mathrm{ULCI}=$ The upper bound within the $95 \%$ confidence interval

외모관리행동을 상, 중, 하로 나누어 희망의 조건부 효과를 시각화한 결과는 [그림 3]과 같다. 세 조건 모두 희망이 증가할 때 성공적 노화도 증가하였다.

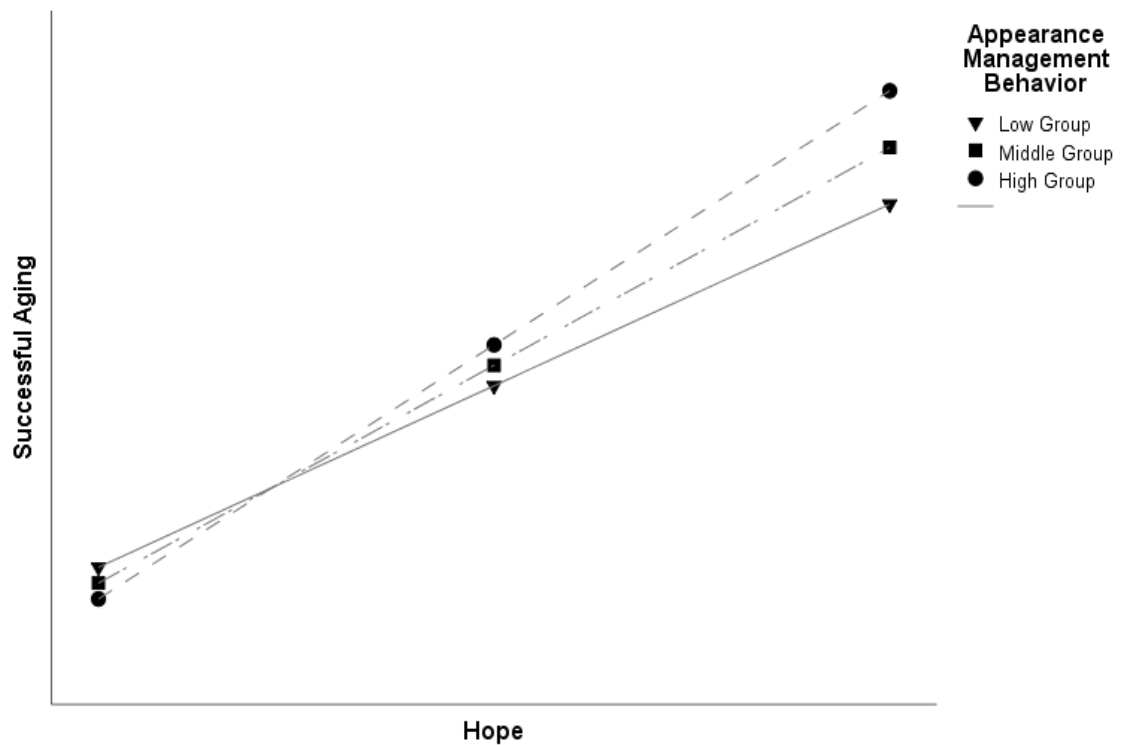

[그림 3] 외모관리행동의 조절효과

[Fig. 3] Moderating Effect of Appearance Management Behavior

그러나 외모관리행동이 낮은 사람들은 희망이 증가함에 따라 성공적 노화가 증가하는 기울기가 완만하였으나, 외모관리행동이 높은 사람들은 희망이 증가함에 따라 성공적 노화가 증가하는 기울기가 더 가팔랐다. 즉, 희망 수준이 동일하더라도 외모관리행동이 
높은 사람들이 그렇지 않은 사람들에 비해 성공적 노화가 더 많이 향상된다는 것이다.

\section{5. 논의 및 결론}

이 연구는 노인들을 대상으로 희망과 성공적 노화의 관계에서 외모관리행동의 조절효과를 파악하기 위해 수행되었으며, 연구 결과를 토대로 논의를 하면 다음과 같다.

첫째, Pearson 상관분석 결과 희망, 외모관리행동 및 성공적 노화 간에는 모두 통계적으로 유의미한 정적 상관관계가 있었다. 즉, 희망이 높을수록, 외모관리행동과 성공적 노화도 높아진다는 것인데, 이러한 결과는 성공적 노화, 외모관리행동, 신체이미지 및 희망 간에 정적 상관관계가 있고[11], 성공적 노화와 희망은 정적 상관이 있었다는[10] 연구 결과와 흐름을 같이 한다.

둘째, 희망과 성공적 노화의 관계를 외모관리행동이 조절하였고, 외모관리행동 값이 증가할수록 희망의 조건부 효과도 증가하였다. 구체적으로 외모관리행동이 높은 사람들은 그러지 않은 사람에 비해 희망이 동일하게 증가하더라도 성공적 노화가 더 많이 증가하였다. 성공적 노화에 대한 희망의 효과는 외모관리행동에 의존한다. 노인들은 노화에 대한 고정관념과 사회적 낙인을 거부하기 위해 외모관리행동을 하고[19], 이러한 행동은 희망 $\rightarrow$ 성공적 노화의 관계를 더욱더 강하게 만든다는 것이다. 이러한 결과는 노인의 신체상과 성공적 노화의 관계에서 외모관리행동의 조절된 매개효과가 있었다는 연구 결과가 뒷받침한다[11].

희망이 높은 노인들은 지속적인 외모관리행동을 통해 성공적 노화를 이룰 확률이 더 높아진다는 프로세스가 확인되었다. 하지만 희망이 성공적 노화의 원인이라 하더라도 짧은 시간 안에 희망의 수준을 끌어올리기란 시간과 노력이 필요하다. 희망 수준이 낮은 노인도 외모관리행동을 하면 성공적 노화를 높일 수 있다는 것이다.

본 연구는 희망이 성공적 노화로 가는 경로에서 외모관리행동의 조절효과를 분석함으로써, 노년학, 사회복지학, 미용학 등 각 분야에서 이루어졌던 연구 결과를 통합하여 성공적 노화 증진을 위한 새로운 모델을 검증하였다는 점에서 의의가 있다. 그럼에도 후속연구를 위하여 다음과 같이 제언하고자 한다.

이 연구를 통해 외모관리행동의 중요성을 파악하였다. 따라서 노인이 손쉽게 할 수 있는 외모관리행동을 활용한 성공적 노화 프로그램 개발과 적용이 필요하다. 또한 성공적 노화와 외모관리행동을 다룬 연구가 아직은 부족하다. 따라서 이 관계에 영향하는 변인들을 탐색하는 후속 연구가 뒤따라야 할 것이다.

\section{6. 감사의 글}

이 논문은 2019년 대한민국 교육부와 한국연구재단의 지원을 받아 수행된 연구임 (NRF-과제번호)(NRF-2019S1A5B5A02045616) 


\section{References}

[1] J. Angus, P. Reeve, Ageism: A threat to "aging well” in the 21st century, Journal of Applied Gerontology, (2006), Vol.25, No.2, pp.137-152, DOI: https://doi.org/10.1177/0733464805285745

[2] B. J. Jeon, Relationship Between Health Status, Successful Aging by Family Type of Elderly and Moderating Effects of Social Network, Journal of Wellness, (2017), Vol.12, No.1, pp.203-216, DOI: https://doi.org/ 10.21097/ksw.2017.02.12.1.203

[3] C. R. Snyder, C. Harris, J. R. Anderson, S. A.Holleran, L. M. Irving, S. T. Sigmon, L. Yoshinobu, J. Gibb, C. Langelle, P. Harney, The will and the ways: Development and validation of an individual-differences measure of hope, Journal of Personality and Social Psychology, (1991), Vol.60, No.4, pp.570-585, DOI: https://doi.org/10.1037/00223514.60.4.570

[4] K. R. Lee, J. H. Park, Relationships between positive psychological capital, social support, learning flow and successful aging of older adult learners, Journal of Lifelong Learning Society, (2021), Vol.17, No.1, pp.147-172, DOI: https://doi.org/10.26857/JLLS.2021.2.17.1.147

[5] P. H. Bloch, M. L. Richins, You look "mahvelous": The pursuit of beauty and the marketing concept, Psychology \& Marketing, (1992), Vol.9, No.1, pp.3-15, DOI: https://doi.org/10.1002/mar.4220090103

[6] C. M. Youssef, F. Luthans, Positive organizational behavior in the workplace: The impact of hope, optimism, and resilience, Journal of management, (2007), Vol.33, No.5, pp.774-800, DOI: https://doi.org/10.1177/ 0149206307305562

[7] C. R. Snyder, D. B. Feldman, J. D. Taylor, L. L. Schroeder, V. H. Adams 11l, The roles of hopeful thinking in preventing problems and enhancing strengths, Applied and Preventive Psychology, (2000), Vol.9, No.4, pp.249-269, DOI: https://doi.org/10.1016/S0962-1849(00)80003-7

[8] A. D. Ong, L. M. Edwards, C. S. Bergeman, Hope as a source of resilience in later adulthood, Personality and individual differences, (2006), Vol.41, No.7, pp.1263-1273, DOI: https://doi.org/10.1016/j.paid.2006.03.028

[9] J. W. Rowe, R. L. Kahn, Successful aging 2.0: Conceptual expansions for the 21st century, The Journals of Gerontology: Series B, (2015), Vol.70, No.4, pp.593-596, DOI: https://doi.org/10.1093/geronb/gbv025

[10] Y. K. Hwang, C. S. Lee, The dual mediating effects of growth mindset and hope in the relationship between body image and successful aging of the elderly, Journal of Industrial Convergence, (2020), Vol.18, No.1, pp.87-96, DOI: https://doi.org/10.22678/JIC.2020.18.1.087

[11] Y. K. Hwang, C. S. Lee, The relationships between body image, hope, and successful aging of elders: a moderated mediation model of appearance management behavior, Journal of Public Health and Development, (2021), Vol.19, No.2, pp.102-119.

[12] S. B. Kaiser, The social psychology of clothing: symbolic appearances in context, New York: Macmillan Publishing Company, (1990)

[13] J. Y. Lee, K. S. Park, Study on the theory of planned behavior applied to appearance management behavior: Focused on skin care, makeup, apparel, hair and weight management behaviors, Korean Journal of Human Ecology, (2012), Vol.21, No.2, pp.331-347, DOI: http://dx.doi.org/10.5934/KJHE.2012.21.2.331

[14] J. H. Lee, C. S. Kim, Comparison of the purchase criteria and fashion information sources for the middle-aged and elderly women's fashion markets segmented based on benefits sought, Family and Environment Research, (2007), Vol.45, No.5, pp.39-49, UCI: G704-000012.2007.45.5.004

[15] Y. K. Hwang, C. S. Lee, Baby face makeup awareness and subjective wellbeing of Korean women: The moderating effect of appearance management behavior, International Journal of Pure and Applied Mathematics, (Special Issue), (2018), Vol.118, No.24, pp.1-15.

[16] Y. H. Choi, H. K. Lee, D. G. Lee, Validation of the Korean version of Snyder's dispositional hope scale, Korean Journal of Social and Personality Psychology, (2008), Vol.22, No.2, pp.1-16, DOI: 10.21193/kjspp.2008.22.2.001

[17] C. S. Lee, Differences in the awareness of successful ageing between adolescents and old adults, Journal of Family 
The Relationship between Hope and Successful Aging of Elders: A Moderation Model of Appearance Management Behavior

Relations, (2007), Vol.12, No.3, pp.85-107, UCI: G704-001334.2007.12.3.009

[18] A. F. Hayes, Introduction to mediation, moderation, and conditional process analysis: A regression-based approach, Guilford publications, (2017)

[19] P. Öberg, L. Tornstam, Youthfulness and fitness: Identity ideals for all ages?, Journal of Aging and Identity, (2001), Vol.6, No.1, pp.15-29, DOI: 10.1023/A:1009524612420 